\title{
Indications for removal of impacted mandibular third molars and associated pathologies
}

\author{
Sushil Subedi*1 ${ }^{1 D}$, Ujjwal Koirala ${ }^{1}$, Bijayata Shrestha ${ }^{2}$ \\ 'Department of Oral and Maxillofacial Surgery, 2Department of Oral Pathology, Gandaki Medical college, Pokhara
}

\begin{abstract}
Introduction: The purpose of this study was to assess the various indications of impacted mandibular third molar removal and pathologies associated with it. Methods: A retrospective cross-sectional study was conducted in the Department of Oral Surgery, Gandaki Medical College. The clinical case records from September 2016 to August 2019 were retrieved, reviewed, and analyzed. Surgically removed impacted mandibular third molars for which orthopantomogram were available and the lesions verified histologically were included in the study. Orthopantomograms were studied to determine the angular position of the impacted mandibular third molars and associated pathology. The data was entered in SPSS 20 and descriptive statistics was applied. Results: A total of 1344 impacted mandibular third molars (Male-709, 52.8\%; Female - 635, 47.2\%) were surgically extracted during the three-year period. The majority of patients (36.5\%) were in the age groups of 25 - 34 years with a higher incidence of mesioangular impaction (33\%). Recurrent pericoronitis (62.9\%) was the most common indication followed by caries $(11.7 \%)$. The radiographically detectable lesion was seen in 471 (35\%) cases out of which 304 (64.5\%) were symptomatic at the time of extraction. Among137 histopathologically diagnosed cases, chronic inflammatory lesion $(76,55.9 \%)$ was the most common finding. Conclusion: Awareness of the indications for removal of impacted mandibular third molars helps in proper management and prevention of future complications associated with retention and delayed extraction of such teeth. So, regular and periodic clinical and radiographic examination is required for patients with impacted mandibular third molars.
\end{abstract}

Keywords: Impacted mandibular third molar, indication, pathology, surgical extraction.

\section{Correspondence to: \\ Dr Sushil Subedi \\ Associate Professor, Department of Oral and \\ Maxillofacial Surgery \\ Gandaki Medical College, Pokhara, Nepal \\ E-mail:_drsushilcods@gmail.com}

Submitted: July 17, 2020

Accepted: November 1, 2020

To cite: Subedi S, Koirala U, Shrestha B. Indications for removal of impacted mandibular third molars and associated pathologies. JGMC Nepal. 2020;13(2):134-9.

DOI: $10.3126 /$ jgmcn.v13i2.31947

\section{INTRODUCTION}

An impacted tooth can be defined as one that is prevented from erupting up to the occlusal level because of malposition, interference, or lack of space in the arch. Since the mandibular third molars are the last teeth to erupt in the arch there is a higher prevalence of them being impacted. ${ }^{1}$ The impacted mandibular third molar may be associated with pathological changes including pericoronitis, an increased risk of caries and periodontal disease in adjacent teeth, and orthodontic problems in later life or remain asymptomatic. There is always a debate on whether to retain or extract an asymptomatic impacted mandibular third molar. Most of the time third molars are considered as a troublemaker and functionally non-essential thus extracted most frequently. ${ }^{2}$

The decision of retaining or removing of impacted mandibular third molars often may become very complex. Surgical removal of the impacted third molar may expose the patients to the risks of surgery such as nerve damage, dry socket, infection, damage 
to the adjacent teeth, bleeding, fracture of the mandible, and rarely death. ${ }^{3}$ At the same time, retention of the impacted third molar may lead to the development of pathologies requiring more extensive surgery that too at an older age when surgery itself is more complicated due to systemic conditions. Therefore, a surgeon must weigh the risk-benefit ratio before choosing the appropriate treatment option.,4

There is paucity of literature on the common indications of surgical removal and common pathologies associated with impacted mandibular third molar in Nepal. So, this study was conducted with an objective to assess the various indications of impacted mandibular third molar removal and pathologies associated with it.

\section{METHODS}

A retrospective cross-sectional study was conducted from November- December 2019 using the records of all the patients who underwent surgical removal of impacted mandibular third molars during a three years period (September 2016 to August 2019) in the Department of Oral and Maxillofacial Surgery, Gandaki medical college, Pokhara, Nepal. Ethical approval for the study was obtained from the Nepal health research council (Approval no. 342/2019). The records of all the patients who underwent surgical removal of impacted mandibular third molar under local anesthesia during the study period were retrieved, reviewed, and analyzed. Impacted third molars which were either fully covered with bone or partially erupted, but prevented from reaching the occlusal plane and those cases for which orthopantomogram were available and the pathological cases in which lesions were verified histologically were included in this study. Mandibular third molars that were fully erupted to the level of the occlusal plane and those patients in whom a surgical removal was performed after failure of forceps extraction were excluded from the study. Cases in which lesions were not verified histologically were also excluded from this study. Each case record was reviewed to determine the reason recorded by the operating surgeon for the removal of the third molar. The following indications of removal of impacted mandibular $3^{\text {rd }}$ molar were recorded: periapical pathology, caries of impacted mandibular $3^{\text {rd }}$ molar, pericoronitis, fracture of the tooth, disease of follicle including cyst/tumor, resorption of the adjacent tooth, teeth impending reconstructive jaw surgery, the tooth involved in or within the field of tumor resection and periodontitis. Orthopantomogram of the cases included were examined to determine the angular position and any associated pathologies. The angular position of the impacted mandibular $3^{\text {rd }}$ molar with reference to the angle formed between the intersected longitudinal axes of the second and third molars included in this study was determined using Winter's classification. ${ }^{5}$ The following radiographic lesions were recorded: caries, pericoronal radiolucent areas around the impacted mandibular third molar, periapical radiolucent areas related to the impacted and partially erupted mandibular third molars, and external resorption of adjacent tooth. A single investigator viewed each radiograph, and to check for the diagnostic reproducibility of the examiner, a second observer examined 40 radiographs with detectable radiographic lesions daily for 5 consecutive days in random orders. No difference between the 2 observers was found. The data was entered in SPSS 20 and descriptive statistics were applied.

\section{RESULTS}

A total of 1344 impacted mandibular third molars were surgically extracted during a three year period. The female to male ratio of the patients who underwent removal was 1:1.2 (Male-709, 52.8\%; Female - 635, 47.2\%). The age of the patients ranged from $18-80$ years and the majority $(n=491$, $36.5 \%$ ) of the extracted impacted mandibular $3^{\text {rd }}$ molar were from the age range of 25 to 34 years. Recurrent pericoronitis was the most frequent indication for removal of the teeth $(846,62.9 \%)$. A significant number of impacted mandibular third molars studied showed either caries $(157,11.7 \%)$ or adjacent tooth resorption $(126,9.4 \%)$ and 52 (3.9\%) of the cases were disease of the dental follicle involving cyst, or tumors (as shown in Table 1). The mesioangular impacted mandibular third molar was most frequently extracted (443, $33 \%$ ) followed by vertical $(423,31.5 \%$ ) (as shown in Table 2). Among 1344 impacted mandibular third molar removed, 471 (35\%) cases showed radiographically detected lesions out of which 167 (35.5\%) were asymptomatic at the time of extraction (as shown in Table 3 ).

Table 1. Indications of removal of impacted mandibular $3^{\text {rd }}$ molar

\begin{tabular}{lr}
\hline Indications for removal & Frequency (\%) \\
Caries involving mandibular $3^{\text {rd }}$ molar & $157(11.7)$ \\
Periapical pathology & $84(6.3)$ \\
External resorption of the adjacent tooth & $126(9.4)$ \\
Repeated episodes of pericoronitis & $846(62.9)$ \\
Fracture of tooth & $28(2.1)$ \\
The disease of follicle including cyst or tumor & $52(3.9)$ \\
Tooth/teeth impending surgery or & $18(1.3)$ \\
reconstructive jaw surgery & $9(0.7)$ \\
Tooth involved in or within the field of tumor & \\
resection & $24(1.8)$ \\
Chronic Periodontitis & \\
\hline
\end{tabular}

A total of 136 specimens associated with impacted third molars were diagnosed histologically. Among them, the most common cystic lesion was a radicular cyst $(8,5.9 \%)$ followed 
by dentigerous cyst $(5,3.7 \%)$. The most common histological finding was chronic inflammatory lesion $(76,55.9 \%)$ which was followed by dental follicle $(36,26.4 \%)$. Four cases (2.9\%) were associated with ameloblastoma and three cases (2.2\%) with squamous cell carcinoma (as shown in Table 4).

Table 2. Angulation and side of impacted mandibular $3^{\text {rd }}$ molar

\begin{tabular}{cc}
\hline Angulation & Frequency (\%) \\
Mesioangular & $443(33.0)$ \\
Horizontal & $182(13.5)$ \\
Vertical & $423(31.5)$ \\
Distoangular & $278(20.7)$ \\
Others* & $18(1.3)$ \\
Side & \\
Right & $705(52.5)$ \\
Left & $639(47.5)$
\end{tabular}

Others*= Lingoversion, buccoversion, and inverted

Table 3. Radiographic lesion as observed in the orthopantomogram and their association with clinical symptoms

\begin{tabular}{cccc}
\hline $\begin{array}{c}\text { Pathologies } \\
\text { observed }\end{array}$ & $\begin{array}{c}\text { Frequency } \\
\text { (\%) }\end{array}$ & $\begin{array}{c}\text { Clinically } \\
\text { symptomatic } \\
\text { n (\%) }\end{array}$ & $\begin{array}{c}\text { Clinically } \\
\text { Asymptomatic } \\
\text { n (\%) }\end{array}$ \\
$\begin{array}{c}\text { Caries in } \\
\text { impacted } \\
\text { mandibular } 3^{\text {rd }} \\
\text { molar }\end{array}$ & $157(33.3)$ & $113(72.0)$ & $44(28.0)$ \\
$\begin{array}{c}\text { Periapical } \\
\text { radiolucency } \\
\text { External }\end{array}$ & $84(17.8)$ & $56(66.7)$ & $28(33.3)$ \\
$\begin{array}{c}\text { resorption of } \\
\text { adjacent } 2^{\text {nd }}\end{array}$ & $126(26.7)$ & $58(46.0)$ & $68(54.0)$ \\
$\begin{array}{c}\text { molar } \\
\text { The disease of } \\
\text { follicle including } \\
\text { cyst and tumor }\end{array}$ & $52(11.0)$ & $34(65.4)$ & $18(34.6)$ \\
$\begin{array}{c}\text { Fractured teeth } \\
\text { Chronic }\end{array}$ & $28(6)$ & $27(96.4)$ & $1(3.57)$ \\
periodontitis & $24(5)$ & $16(66.6)$ & $8(33.4)$ \\
$\begin{array}{c}\text { Total radio- } \\
\text { graphically }\end{array}$ & $471(35)$ & $304(64.5)$ & $167(35.5)$ \\
\hline detected lesions & & & \\
\hline
\end{tabular}

Table 4. Histological findings of the lesions associated with impacted mandibular third molars

\begin{tabular}{|c|c|c|c|c|}
\hline Lesion & Type & Frequency & $\% *$ & $\% \#$ \\
\hline Cyst & $\begin{array}{l}\text { Radicular cyst } \\
\text { Dentigerous cyst } \\
\text { Odontogenic } \\
\text { keratocyst } \\
\text { Total }\end{array}$ & $\begin{array}{c}8 \\
5 \\
4 \\
17\end{array}$ & $\begin{array}{l}5.9 \\
3.7 \\
2.9 \\
12.5\end{array}$ & $\begin{array}{l}1.7 \\
1.06 \\
0.84 \\
3.8\end{array}$ \\
\hline $\begin{array}{l}\text { Periapical } \\
\text { inflammation }\end{array}$ & $\begin{array}{l}\text { Chronic } \\
\text { inflammatory } \\
\text { lesion }\end{array}$ & 76 & 55.9 & 16 \\
\hline Dental follicle & Dental follicle & 36 & 26.4 & 7.6 \\
\hline \multirow[t]{2}{*}{ Tumors } & $\begin{array}{l}\text { Ameloblastoma } \\
\text { Squamous cell } \\
\text { Carcinoma }\end{array}$ & $\begin{array}{l}4 \\
3\end{array}$ & $\begin{array}{l}2.9 \\
2.2\end{array}$ & $\begin{array}{l}0.84 \\
0.6\end{array}$ \\
\hline & Total & 7 & 5.1 & 1.5 \\
\hline
\end{tabular}

*Percentage of total histological findings $(\mathrm{n}=136)$
"Percentage of the mandibular third molar with radiographic lesions $(n=471)$

\section{DISCUSSION}

Third molars are the last teeth to erupt in the oral cavity and this usually happens between the age of 18 to 24 years. Impaction may be associated with pathological changes including pericoronitis, an increased risk of caries and periodontal disease in adjacent teeth, and orthodontic problems in later life or remain asymptomatic. The prevalence of impacted mandibular third molar ranges from $16.7 \%$ to $96.5 \% .^{1,6,7}$ Despite the substantial amount of literature dedicated to the debate on whether or not to prophylactically remove third molars, there is still disagreement and controversy among general dental practitioners and oral surgeons as to what constitutes best practice. ${ }^{4}$

Guidelines for the management of third molars proposed by the National Institute for Clinical Excellence (NICE) advises against the routine prophylactic removal of pathology-free impacted third molars. According to the NICE guidelines, surgical removal of impacted third molars should be limited to patients with evidence of pathology which includes unrestorable caries, non-treatable pulpal and/or peri-apical pathology, cellulitis, abscess and osteomyelitis, internal/ external resorption of the tooth or adjacent teeth, recurrent episodes of pericoronitis, fracture of the tooth, disease of follicle including cyst/tumor, tooth/teeth impending surgery or reconstructive jaw surgery, chronic periodontitis and when a tooth is involved in or within the field of tumor resection. ${ }^{8}$ However, J Mansoor et $\mathrm{al}^{9}$ blamed NICE guidelines for not being based on sound clinical evidence and not considering the consequence of non-extraction of impacted third molars.

The presence of partial and/or soft tissue impacted third molar is associated with a significantly increased risk of increased plaque accumulation and pericoronitis. Recurrent pericoronitis was the most common indication of surgical removal of impacted mandibular third molar in the current study. Similar findings were reported in the literature. ${ }^{10,11}$ The first episode of pericoronitis unless very severe is not considered as an indication of surgery and is managed conservatively in our institution. However, the second or subsequent episode of pericoronitis is considered as an indication of third molar removal. This might be the reason for the highest incidence of impacted third molar removal under the age group of 25 to 34 years in the current study. There was a slightly higher prevalence of impacted mandibular third molar removal in males (52.8\%) as compared to females. Similar frequencies were reported by previous studies. ${ }^{12,13}$ 
There is a higher caries risk in partially impacted third molar and the distal surface of the second molar due to relative inaccessibility of cleaning. The food gets trapped between the second molar and occlusal surface of the third molar making it more prone to dental caries development. Often caries involves the occlusal surface of the third molar and the radicular portion of the second molar making it difficult to restore. In cases of late presentation, the third molar and second molars both end up on extraction. Caries involvement of the third molar was the second most common indication of extraction in the current study similar to the previous studies. ${ }^{14,15}$ The increased risk of distal carries on the second molar supports the prophylactic removal of the impacted third molar to avoid future complications. ${ }^{14,15}$ At the same time Mettes et $\mathrm{al}^{16}$ in their review reported that due to the lack of randomized control trials and long-term cross-sectional studies insufficient evidence was found to support or refute routine prophylactic removal of asymptomatic impacted third molars in adults and suggested watchful monitoring may be a more prudent strategy. In our institute, none of the asymptomatic disease-free impacted third molars were removed prophylactically.

In the current study, a relatively higher frequency of the root resorption $(9.4 \%)$ of the adjacent second molar was seen. The root resorption of the second molar was more frequently associated with class II level B mesioangularly impacted mandibular third molars. This finding is supported by other previous studies of Nitzanet $\mathrm{al}^{17}$ and Oenning AC et $\mathrm{al}^{18}$ and is in disagreement with other studies too. ${ }^{19}$ There is very limited clinical evidence suggesting the impacted mandibular third molar as a contributing factor for the late incisors crowding and it is always a matter of debate. ${ }^{20-22}$ In our institute, none of the third molars were extracted for orthodontic purposes.

In the earlier studies, the prevalence of cyst formation associated with the impacted mandibular third molars was variable and, therefore, difficult to interpret. This might be due to different diagnostic criteria. According to Stephens et $\mathrm{al}^{23}$ a pericoronal radiolucency greater than $2.5 \mathrm{~mm}$ was diagnostic criteria of the follicular cyst which leads to a false-positive result and a higher prevalence rate. In the present study, we used both radiographic and histopathological findings to define a cyst. The prevalence of cyst and tumor formation associated with the impacted mandibular third molar in this study (3.9\%) was higher than that reported previous studies ${ }^{12,24}$ and lower than reported by El-Khateebet $\mathrm{al}^{25}$ in their radiographic assessment of impacted teeth and associated pathology. However, this result of the prevalence of cyst formation was similar to the mean probability of $3.51 \%$ of cystic changes calculated based on a comprehensive review of the literature. ${ }^{26}$ Among cystic lesions, the most frequent pathology was the radicular cyst associated with decayed third molar followed by the dentigerous cyst and lastly odontogenic keratocyst. On histopathological examination, most of the periapical pathologies were chronic inflammatory tissue and most of the pericoronal lesions were dental follicle. In the current study association of impacted third molar with tumors was less than $1 \%$ which was in concurrence with previous studies. $^{24}$

The prevalence of radio-graphically detected pathology was $35 \%$ in the current study. Among them, only $64.5 \%$ were symptomatic at the time of presentation. This result suggests that the absence of symptoms associated with impacted mandibular third molars does not mean that they are not associated with disease or pathology. Similar findings were reported in the systematic review of Marciani RD. ${ }^{27}$ Therefore a regular periodic radiological and clinical examination should be carried out for patients whose impacted third molars are not removed surgically even in absence of symptoms.

The normal development and path of eruption of the mandibular third molars are in the anterosuperior direction. ${ }^{28}$ This might be the reason for the highest number of the impacted mandibular third molar to be impacted in the mesioangular pattern in this study similar to the previous studies., ${ }^{9,1029}$ A new parameter of indication for impacted mandibular third molar extraction was preparation for orthognathic surgery. Although, limited clinical evidence is available supporting the association between the presence of impacted mandibular third molar and incidence of a bad split during osteotomy, impacted mandibular third molars are extracted six months before bilateral sagittal split osteotomy in our institute..$^{30}$

\section{CONCLUSION}

There was a high prevalence of mesioangular mandibular third molar impaction and recurrent pericoronitis was the most common indication for surgical removal. Awareness of the indications for removal of impacted mandibular third molars will help in the proper management and prevention of future complications associated with retention and delayed extraction of such teeth. The absence of symptoms does not necessarily mean the absence of pathology, therefore, regular and periodic clinical and radiographic examination is required for patients with retained impacted mandibular third molars. 
Reccomendation: Wewould recommend further prospective research involving multiple tertiary hospitals all over Nepal. We would also like to recommend to conduct a randomized control trials in the future comparing prophylactic removal of impacted third molars with management by deliberate retention will be more helpful in decision making for prophylactic removal of impacted third molars

Limitations of the study: The limitations of the study were the retrospective nature of the study, which did not allow us to study how the impacted third molars respond to conservative management on long term follow-up and this was a single institutional experience which limits the generability of the result.

\section{Acknowledgment: None.}

\section{Conflict of interest: None}

\section{REFERENCES}

1. Kumar Pillai A, Thomas S, Paul G, Singh SK, Moghe S. Incidence of impacted third molars: A radiographic study in People's Hospital, Bhopal, India. J Oral Biol Craniofac Res. 2014;4(2):76-81. DOI: 10.1016/j.jobcr.2014.04.001

2. Kaveri GS, Prakash S. Third molars: a threat to periodontal health?? J Maxillofac Oral Surg. 2012;11(2):220-3. DOI: 10.1007/s12663-011-0286-x

3. Bouloux GF, Steed MB, Perciaccante VJ. Complications of third molar surgery. Oral Maxillofac Surg Clin North Am. 2007;19(1):117-28. DOI: 10.1016/j.coms.2006.11.013

4. Rafetto LK. Controversy, evidence, and third molar management. Atlas Oral Maxillofac Surg Clin North Am. 2012;20(2):253-61. DOI: 10.1016/j.cxom.2012.06.004

5. Hashemipour MA, Tahmasbi-Arashlow M, FahimiHanzaei F. Incidence of impacted mandibular and maxillary third molars: a radiographic study in a Southeast Iran population. Med Oral Patol Oral Cir Bucal. 2013;18(1):e140-e145. DOI: 10.4317/medoral.18028

6. Grover PS, Lorton L. The incidence of unerupted permanent teeth and related clinical cases. Oral Surg Oral Med Oral Pathol. 1985;59(4):420-5. DOI: 10.1016/00304220(85)90070-2

7. Dachi SF, Howell FV. A survey of 3, 874 routine full-month radiographs. II. A study of impacted teeth. Oral Surg Oral Med Oral Pathol. 1961;14:1165-9. DOI: 10.1016/00304220(61)90204-3

8. National Institute for Health and Care Excellence (NICE). Guidance on the Extraction of Wisdom Teeth: NICE technology appraisal guidance [TA1]. 2000 Mar:4.
Available from: https://www.nice.org.uk/guidance/ ta1/resources/guidance-on-the-extraction-of-wisdomteeth-pdf-63732983749 (Accessed 30th October 2020)

9. Mansoor J, Jowett A, Coulthard P. NICE or not so NICE? Br Dent J. 2013;215(5):209-12. DOI: 10.1038/ sj.bdj.2013.832

10. Krishnan B, Sheikh MH, Rafa el G, Orafi H. Indications for removal of impacted mandibular third molars: a single institutional experience in Libya. J Maxillofac Oral Surg. 2009;8(3):246-8. DOI: 10.1007/s12663-009-0060-5

11. Patel S, Mansuri S, Shaikh F, Shah T. Impacted mandibular third molars: a retrospective study of 1198 cases to assess indications for surgical removal, and correlation with age, sex and type of impaction-a single institutional experience. J Maxillofac Oral Surg. 2017;16(1):79-84. DOI: $10.1007 / \mathrm{s} 12663-016-0929-\mathrm{z}$

12. Al-Khateeb TH, Bataineh AB. Pathology associated with impacted mandibular third molars in a group of Jordanians. J Oral Maxillofac Surg. 2006;64(11):1598602. DOI: $10.1016 /$ j.joms.2005.11.102

13. Venu Gopal Reddy K. Distribution of third molar impactions among rural and urban dwellers in the age group of 22-30 years in south India: a comparative study. J Maxillofac Oral Surg. 2012;11(3):271-5. DOI: 10.1007/ s12663-011-0320-z

14. McArdle LW, McDonald F, Jones J. Distal cervical caries in the mandibular second molar: an indication for the prophylactic removal of third molar teeth? Update. Br J Oral Maxillofac Surg. 2014;52(2):185-9. DOI: 10.1016/j. bjoms.2013.11.007

15. McArdle LW, Renton TF. Distal cervical caries in the mandibular second molar: an indication for the prophylactic removal of the third molar? Br J Oral Maxillofac Surg. 2006;44(1):42-5. DOI: 10.1016/j. bjoms.2005.07.025

16. Mettes TD, Ghaeminia H, Nienhuijs ME, Perry J, van der Sanden WJ, Plasschaert A. Surgical removal versus retention for the management of asymptomatic impacted wisdom teeth. Cochrane Database Syst Rev. 2012;(6):CD003879 DOI: 10.1002/14651858. CD003879.pub3

17. Nitzan D, Keren T, Marmary Y. Does an impacted tooth cause root resorption of the adjacent one? Oral Surg Oral Med Oral Pathol. 1981;51(3):221-4. DOI: 10.1016/00304220(81)90047-5

18. Oenning AC, Melo SL, Groppo FC, Haiter-Neto F. Mesial 
inclination of impacted third molars and its propensity to stimulate external root resorption in second molars-a cone-beam computed tomographic evaluation. J Oral Maxillofac Surg. 2015;73(3):379-86. DOI: 10.1016/j. joms.2014.10.008

19. Yamaoka M, Furusawa K, Ikeda M, Hasegawa T. Root resorption of mandibular second molar teeth associated with the presence of the third molars. Aust Dent J. 1999;44(2):112-6. DOI: 10.1111/j.1834-7819.1999. tb00211.x

20. Cheng HC, Peng BY, Hsieh HY, Tam KW. Impact of third molars on mandibular relapse in post-orthodontic patients: A meta-analysis. J Dent Sci. 2018;13(1):1-7. DOI: $10.1016 /$ j.jds.2017.10.005

21. Sidlauskas A, Trakiniene G. Effect of the lower third molars on the lower dental arch crowding. Stomatologija. 2006;8(3):80-4.

22. Bishara SE. Third molars: a dilemma! Or is it? Am J Orthod Dentofacial Orthop. 1999;115(6):628-33. DOI: 10.1016/s0889-5406(99)70287-8

23. Stephens RG, Kogon SL, Reid JA. The unerupted or impacted third molar--a critical appraisal of its pathologic potential. J Can Dent Assoc. 1989;55(3):2017

24. Vigneswaran AT, Shilpa S. The incidence of cysts and tumors associated with impacted third molars. J Pharm Bioallied Sci. 2015;7(Suppl 1):S251-4. DOI: 10.4103/0975-7406.155940
25. El-Khateeb SM, Arnout EA, Hifnawy T. Radiographic assessment of impacted teeth and associated pathosis prevalence. Pattern of occurrence at different ages in Saudi male in Western Saudi Arabia. Saudi Med J. 2015;36(8):973-9. DOI: 10.15537/smj.2015.8.12204

26. Brickley M, Kay E, Shepherd JP, Armstrong RA. Decision analysis for lower-third-molar surgery. Med Decis Making. 1995;15(2):143-51. DOI: 10.1177/0272989X9501500207

27. Marciani RD. Is there pathology associated with asymptomatic third molars? J Oral Maxillofac Surg. 2012;70(9 Suppl 1):S15-9. DOI: 10.1016/j. joms.2012.04.025

28. Vranckx M, Ockerman A, Coucke W, Claerhout E, Grommen B, Miclotte A, et al. Radiographic prediction of mandibular third molar eruption and mandibular canal involvement based on angulation. Orthod Craniofac Res. 2019;22(2):118-23. DOI: 10.1111/ocr.12297

29. Knutsson K, Brehmer B, Lysell L, Rohlin M. Pathoses associated with mandibular third molars subjected to removal. Oral Surg Oral Med Oral Pathol Oral Radiol Endod. 1996;82(1):10-7. DOI: 10.1016/s10792104(96)80371-4

30. Steenen SA, van Wijk AJ, Becking AG. Bad splits in bilateral sagittal split osteotomy: systematic review and meta-analysis of reported risk factors. Int J Oral Maxillofac Surg. 2016;45(8):971-9. DOI: 10.1016/j. ijom.2016.02.011 